Case study

\title{
Archaeometric dating of two limekilns in an industrial heritage site in Calders (Catalonia, NE Spain)
}

\author{
Lluís Casas $^{\mathrm{a}, *}$, Judith Ramírez ${ }^{\mathrm{b}}$, Antònia Navarro ${ }^{\mathrm{b}}$, Boutheina Fouzai ${ }^{\mathrm{c}}$, \\ Eugènia Estop ${ }^{\mathrm{a}}$, Joan Ramon Rosell ${ }^{\mathrm{b}}$ \\ a Universitat Autònoma de Barcelona, Facultat de Ciències, Departament de Geologia, Campus de la UAB, 08193 Bellaterra, Catalonia, Spain

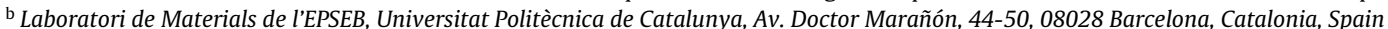 \\ c Université de Tunis El Manar, Faculté des Sciences, Département de Géologie, Campus Universitaire, 2092 Manar II, Tunisia
}

\section{A R T I C L E I N F O}

\section{Article history:}

Received 30 June 2013

Accepted 14 November 2013

Available online $\mathrm{xxx}$

\section{Keywords:}

Archaeometry

Archaeomagnetism

Industrial heritage

Thermoluminescence dating

Metallography

Limekiln

\begin{abstract}
A B S T R A C T
An archaeometric multi-technique approach has been undertaken to date an early industrial (mid19th century) continuous limekiln in Calders (Catalonia, NE Spain). Dating was achieved combining archaeomagnetic and thermoluminescence methods. Metallographic data, oral and written sources also contributed to the dating discussion. A neighboring conventional (i.e. non-continuous) limekiln was dated using its recorded archaeomagnetic direction.
\end{abstract}

(c) 2013 Elsevier Masson SAS. All rights reserved.

\section{Site setting and aim of the research}

The Center for Contemporary Art and Sustainability (CACiS) Forn de la Calç is located in Calders, $50 \mathrm{~km}$ north to Barcelona. The center is hosted in an old (mid-20th century) industrial infrastructure that was devoted to the production of quicklime and it comprises three limekilns and several annexed buildings. The ensemble has been listed within the 150 most representative architectural elements of the Catalan industrial heritage by the national Museum of Science and Technology (mNACTEC). The buildings have been restored and at present host art's exhibits, visual arts projects and performances.

Apart from the restored buildings, in the nearby area, some more kilns have been found that nonetheless are less known. On one hand, about 100 meters east from the CACiS, there is a limekiln adjacent to a country house with a particular morphology. Instead of the traditional cylindrical shape and a moderate height, this kiln has a narrow supply conduct (internal diameter of $1.6 \mathrm{~m}$ at the bottom) with a considerable height $(6.5 \mathrm{~m})$ made of refractory bricks (Fig. 1). This morphology is typical of early industrial (in Spain

\footnotetext{
* Corresponding author. Tel.: +34 935868365; fax: +34 935811263.

E-mail addresses: Lluis.Casas@uab.cat, Lluis.Casas@gmail.com (L. Casas), judith.ramirez@upc.edu (J. Ramírez), antonia.navarro@upc.edu (A. Navarro), fouzai_boutheina@yahoo.fr (B. Fouzai), eugenia.estop@uab.cat (E. Estop), joan.ramon.rosell@upc.edu (J.R. Rosell).
}

mid-19th century) kilns that operated burning continuously [1]. The brick walls have coatings of melting products revealing that high temperatures were reached inside the kiln. A fire was lit at the base and then alternate layers of limestone and fuel (charcoal, coal or wood) were introduced from the top. On the other hand, next to a dirt road some $500 \mathrm{~m}$ east from CACiS, three cylindrical holes ( $\sim 3 \mathrm{~m}$ diameter) excavated in the ground indicate the existence of conventional (i.e. non-continuous) limekilns in the place. The holes correspond to excavated firing chambers of the kilns, one of them is severely cut by the road and it is presently filled with earth, the other two are excavated below the ground level and it is possible to observe that their walls are made of baked clay coated discontinuously by melting products towards the bottom. The simplicity and traditional shape of the chambers (a cylinder slightly urceolate) do not provide any information on the period of use of these kilns.

At present, there is an ongoing project that intends to restore the early industrial kiln to use it for public demonstration events. Characterization and dating of this kiln and the nearby kiln holes has been considered within the framework of this project.

\section{Sampled materials}

Because of its peculiar features, the early industrial kiln (labeled C) focused the sampling operations. Several refractory bricks and slag deposits from the internal walls of the kiln were removed to 


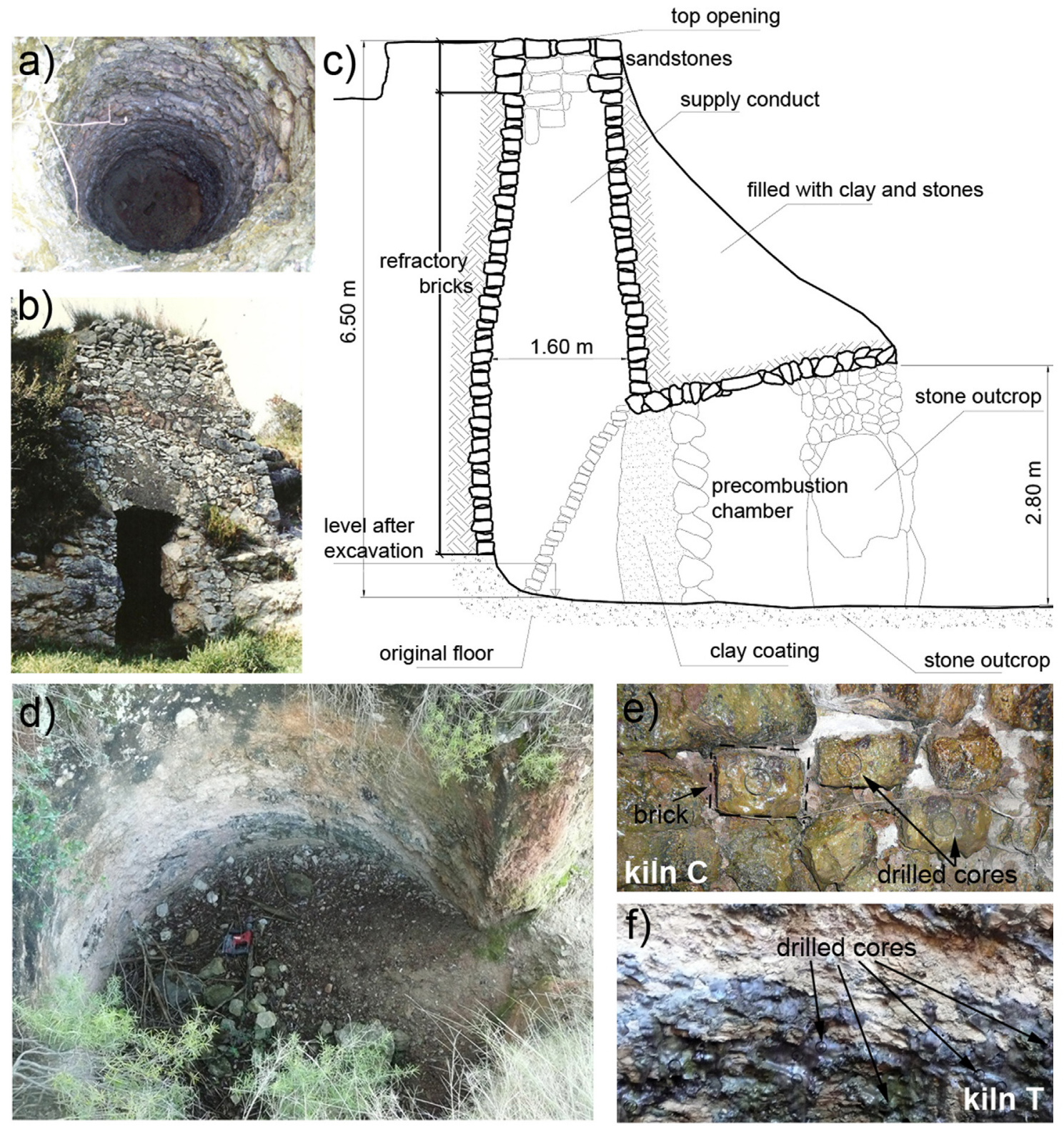

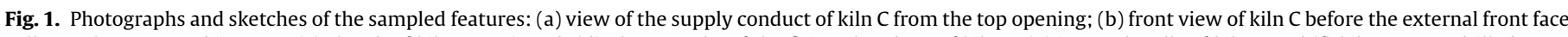

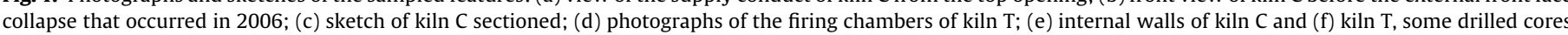
$(\sim 2.5 \mathrm{~cm} \varnothing)$ are indicated on the pictures.

perform magnetic and thermoluminescence analyses. Nineteen oriented cores (labeled from C1 to C19) were also retrieved, circularly and at two different heights, from the internal walls to perform archaeodirectional determinations (Fig. 1e). The in-situ azimuth and dip of the cores were measured using a magnetic compass coupled to a core orienting fixture. Besides the bricks, two iron bars recovered during excavation works inside this kiln were also sampled for analysis. These bars belonged to the baking rack system of the kiln.

One of the conventional kilns was also sampled (labeled T). It consists only of a cylindrical hole (diameter $3.18 \mathrm{~m}$, depth $2.85 \mathrm{~m}$ ) excavated in the clay ground (Fig. 1d) without stone or brick walls, 20 oriented cores (labeled from T1 to T20) were collected circularly from the lower part of the slag-covered walls (Fig. 1f).

The standard palaeomagnetic sampling procedure was applied for both kilns as described in Fouzai et al. [2], each core produced always a single specimen.

\section{Archaeometric methods and data analyses}

\subsection{Archaeomagnetism}

Rock magnetism data was obtained using magnetic susceptibility equipment from Bartington, available at the Geology Department in the Universitat Autònoma, in Barcelona (UAB) consisting of an MS2 susceptibility meter and MS2B and MS2W sensors. The anisotropy of the magnetic susceptibility was evaluated using AMSWIN-BAR software. Archaeodirection determinations were performed at the Paleomagnetic Laboratory of Barcelona (SCT UB-CSIC) and involved stepwise demagnetization of the NRM in a MMTD-80 thermal demagnetizer and measurement of the remaining NRM after each step on a 2G Enterprises superconducting rock magnetometer.

Data were represented as Zijderveld diagrams and selection of the characteristic remanent magnetization (ChRM) was done by 
principal component analyses [3]. Specimens with a maximum angular deviation (MAD) higher than five were removed from the calculation of a mean direction. Mean directions were computed for each kiln following Fisher statistics [4], concentration parameter $k$ and confidence factor $\alpha_{95}$ were also computed.

Probability density functions of possible dates were obtained for each kiln using a Matlab dating tool [5]. The archaeomagnetic data from the kilns were compared with predictions from two geomagnetic models, Jackson et al. [6] and Pavón-Carrasco et al. [7].

\subsection{Thermoluminescence}

A brick originally placed at a height of about $3 \mathrm{~m}$ within the supply conduct of kiln $C$ was used for thermoluminescence analyses. A few grams from it were extracted avoiding surface material, electromagnetic radiation exposure and water looses. Estimates of archaeological dose and annual dose were obtained following the fine grains method [8] using particles with diameters between 2 and $10 \mu \mathrm{m}$.

The archaeological dose was evaluated using the additive dose method for multiple aliquots [9]. A calibrated radioactive source of $\mathrm{Sr}-\mathrm{Y}^{90}$ with a dose rate of $0.0404 \mathrm{~Gy} / \mathrm{s}$ was used as beta emitter. After measuring the thermoluminescent signal, a second irradiation series was performed using a lower dose to identify supralinearity. Alpha-particles efficiency to produce thermoluminescence compared to beta-particles (k-factor) was calculated using ${ }^{241} \mathrm{Am}$ alpha emitter with a dose rate of $0.0297 \mathrm{~Gy} / \mathrm{s}$. All thermoluminescent responses were obtained after heating the aliquots at $90^{\circ} \mathrm{C}$ for $120 \mathrm{~s}$ to suppress non-stable signals. The archaeological dose and the k-factor were obtained using the temperature range corresponding to the plateau in the curve of temperaturedependent natural/irradiated thermoluminescent response [8].

The annual dose was calculated as the sum of alpha, beta and gamma contributors. The activity due to alpha-emitters (U and Th) was measured using a $\mathrm{ZnS}$ detector. The activity due to beta emitters (mainly ${ }^{40} \mathrm{~K}$ ) was measured using a Geiger-Müller counter. Since it was not possible to carry out measurements of environmental dose in situ, gamma ray contribution to annual dose was inferred from a database of regional radiation levels. Conversions from count rate into dose were done following Nambi and Aitken [10]. Alpha dose was corrected taking into account the previously mentioned k-factor.

\subsection{Metallographic microscopy}

The two iron bars from the baking rack system of kiln $\mathrm{C}$ were cut on a chop saw using cutting oil as a coolant. Sections of metal were grinded and polished to produce two sister specimens per bar to be examined under a metallographic microscope (Optika N-400POL). Etching with $2 \%$ nitric acid in ethanol (nital) was performed for one of the sister samples from each bar. Elemental composition of the metallic grains was evaluated using arc/spark optical emission spectrometry (Spectrolab Systems).

\section{Results}

\subsection{Archaeomagnetism}

\subsubsection{Rock magnetism results}

Three types of materials were investigated: bricks (C-Brick) and melting products (C-Slag) from kiln $\mathrm{C}$ and melting products from kiln T (T-Slag), these were in form of cylindrical samples (standard palaeomagnetic cores), chipped and powdered samples.

Frequency-dependent susceptibility $\left(\chi_{\mathrm{FD}}\right)$ values were determined at room temperature for cylindrical samples (Table 1). From the values, different magnetic ensembles can be deduced [11]:
Table 1

Susceptibility measurements at room temperature.

\begin{tabular}{llccrl}
\hline Kiln & $\begin{array}{l}\text { Sample } \\
\text { type }\end{array}$ & $\begin{array}{l}\chi_{\mathrm{LF}} \\
\left(10^{-8} \mathrm{~m}^{3} \mathrm{~kg}^{-1}\right)\end{array}$ & $\begin{array}{l}\chi_{\mathrm{HF}} \\
\left(10^{-8} \mathrm{~m}^{3} \mathrm{~kg}^{-1}\right)\end{array}$ & \multicolumn{1}{l}{$\begin{array}{l}\chi_{\mathrm{FD}} \\
(\%)\end{array}$} & \multicolumn{1}{l}{$\begin{array}{l}\text { AMS } \\
(\%)\end{array}$} \\
\hline $\mathrm{C}$ & Brick & $0.8 \pm 0.3$ & $0.8 \pm 0.3$ & $3.9 \pm 4.0$ & 3.6 to 9.4 \\
$\mathrm{C}$ & $\begin{array}{l}\text { Melting } \\
\text { products }\end{array}$ & $13.2 \pm 3.0$ & $11.6 \pm 2.6$ & $12.1 \pm 1.6$ & 5.0 to 6.6 \\
$\mathrm{~T}$ & $\begin{array}{l}\text { Melting } \\
\text { products }\end{array}$ & $64.0 \pm 23.4$ & $62.3 \pm 23.0$ & $3.3 \pm 1.4$ & 5.1 to 3.1 \\
\hline
\end{tabular}

$\chi_{\mathrm{LF}}$ : specific mass susceptibility at low frequency $(470 \mathrm{~Hz}) ; \chi_{\mathrm{HF}}$ : specific mass susceptibility at high frequency $(4700 \mathrm{~Hz}) ; \chi_{\mathrm{FD}}$ : frequency-dependent susceptibility; AMS: anisotropy of the magnetic susceptibility.

low $\chi_{\mathrm{FD}}$ and $\chi_{\mathrm{LF}}$ values would indicate that pseudo-single domain (PSD) grains dominate the assemblage in C-Brick samples; very high $\chi_{\mathrm{FD}}$ values and moderate $\chi_{\mathrm{LF}}$ values would indicate that single domain (SD) grains dominate in C-Slag samples; and finally low $\chi_{\mathrm{FD}}$ combined with high $\chi_{\mathrm{LF}}$ values would indicate that the signal is dominated by multidomain (MD) grains in T-Slag samples. Their higher $\chi$ values also reveal a higher concentration of magnetic grains for T-Slag samples; these melting products possibly incorporated iron oxide from the clay ground.

The anisotropy of magnetic susceptibility (AMS) was measured on cylindrical samples from 18 measurements for each core; the results are reported in Table 1 . The measured anisotropies are usually around 6\%, showing low dispersion for slag samples, whereas values measured on bricks are a bit more scattered (dispersion could actually be linked to the low susceptibility signal exhibited by brick samples).

Thermomagnetic curves were measured on both powdered and chipped samples, the latter exhibiting better reversibility. Invariably, the susceptibility signal starts to decrease at about $350^{\circ} \mathrm{C}$, this allow aluminium- or titanium-subtituted magnetite to be identified as the main magnetic carrier in both $\mathrm{C}$ and $\mathrm{T}$ samples.

\subsubsection{Archaeodirection results}

All the analyzed specimens exhibited linear Zijderveld diagrams, in many cases the whole NRM defined the ChRM (Fig. 2a). To compute the mean archaeomagnetic direction from kiln C, only two specimens were rejected: C3 with an inconsistent archaeomagnetic direction (attributable to a wrong replacement of a broken core) and $\mathrm{C} 4$ due to $\mathrm{MAD}>5$. All specimens from kiln T were used to compute its mean archaeomagnetic direction. Fig. $2 \mathrm{~b}$ shows the stereographic projection of the directions used to compute both mean directions.

\subsubsection{Archaeomagnetic dating}

The archaeomagnetic results were compared with geomagnetic models. The early industrial typology of kiln $C$ constrain its possible age within the last two centuries, therefore comparison was done using a geomagnetic model covering the last 400 years [6]. The angular values of the model were assumed to have a standard deviation of $0.5^{\circ}[12]$. Fig. 3a shows the obtained probability density functions of possible dates. According to the model, the last use of kiln C should have occurred during 1938 to 1986 at the $95 \%$ confidence level.

The simplicity and the traditional shape of kiln $\mathrm{T}$ do not give any clue on its age and therefore the SCHA.DIF.3K model covering the last 3000 years [7] was initially used. The obtained probability distribution of possible ages (Fig. 3b) indicates a narrow and quite recent time interval (1844 to 1885) at the 95\% confidence level. Dating using Jackson model [6] as reference curve produced a similar date (1833 to 1879) at the same confidence level (Fig. 3c). It is worth to mention that Jackson model for the 20th century match with the international geomagnetic reference field (IGRF) values. 
a)
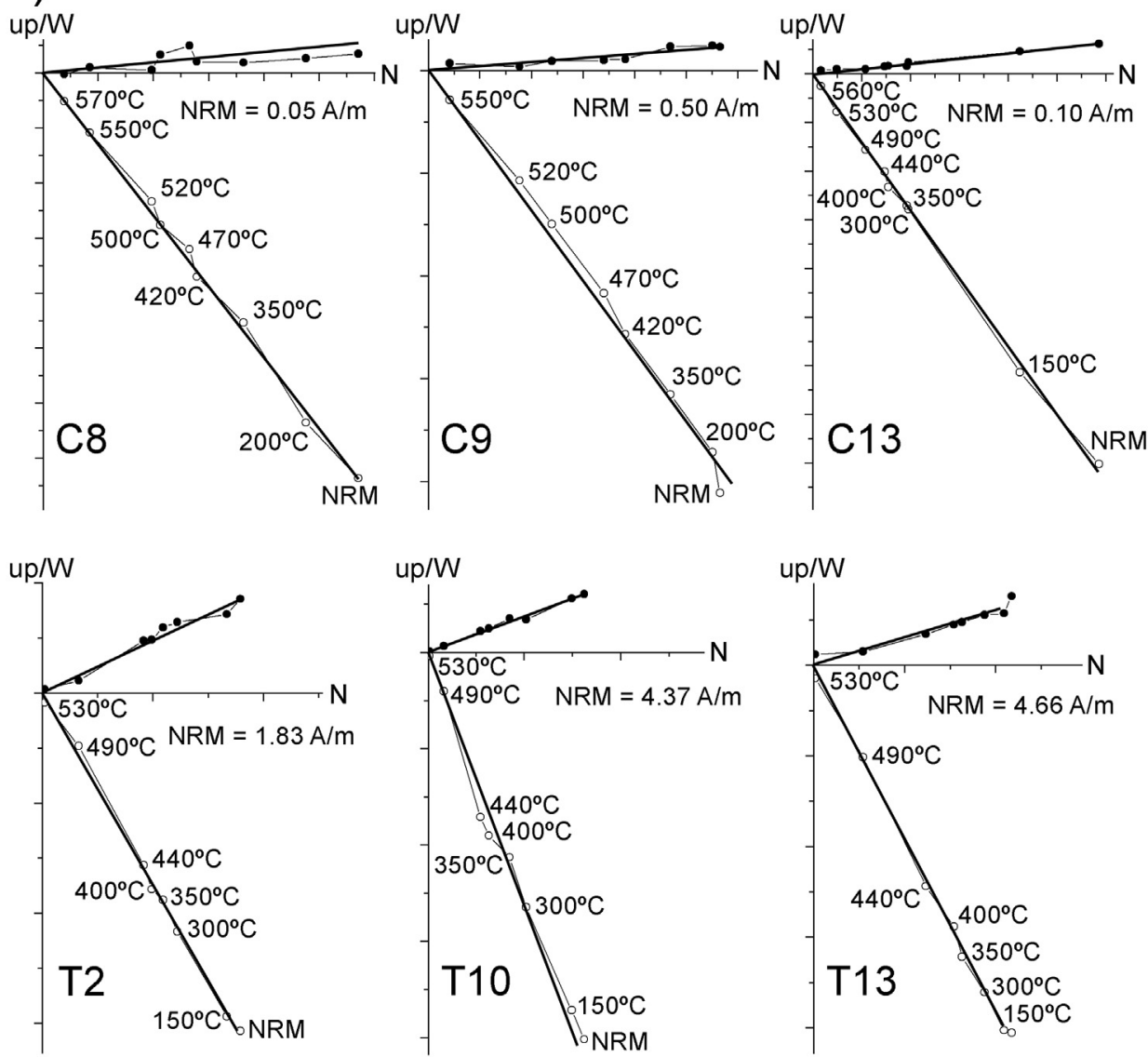

b)

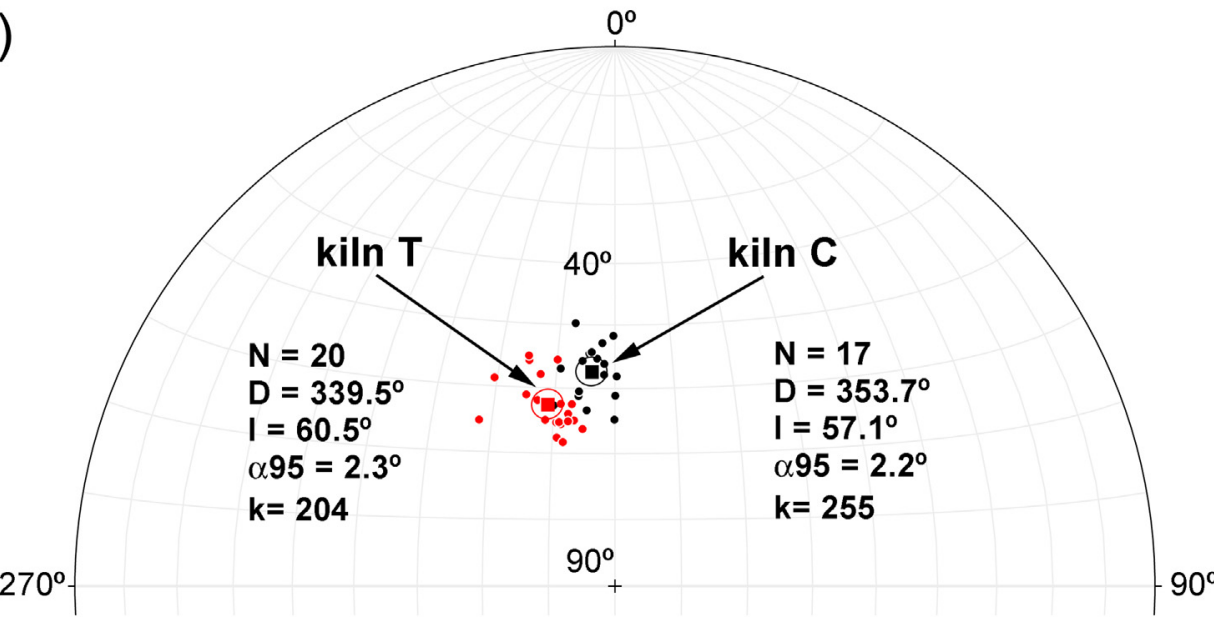

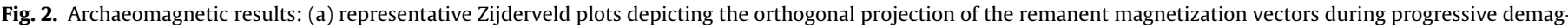

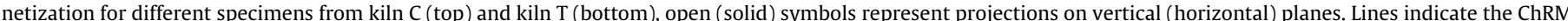

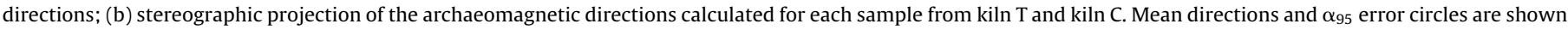

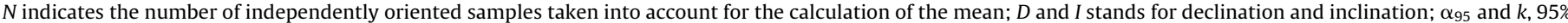
confidence cone of mean directions and precision parameter from Fisher statistics.

Table 2

Summary of the thermoluminescence dating results for kiln C.

\begin{tabular}{|c|c|c|c|c|c|c|c|}
\hline $\begin{array}{l}\text { Plateau range } \\
\left({ }^{\circ} \mathrm{C}\right)\end{array}$ & $\begin{array}{l}\text { Archaeological } \\
\text { dose } \\
\text { (Gy) }\end{array}$ & $\begin{array}{l}\mathrm{K}_{2} \mathrm{O} \\
(\%)\end{array}$ & $\begin{array}{l}\mathrm{H}_{2} \mathrm{O} \\
(\%)\end{array}$ & $\begin{array}{l}\mathrm{H}_{2} \mathrm{O}_{\text {sat }} \\
(\%)\end{array}$ & k-value & $\begin{array}{l}\text { Annual dose } \\
\text { (mGy/year) }\end{array}$ & $\begin{array}{l}\text { Age } \\
\text { (years BP) }\end{array}$ \\
\hline $220-260$ & $0.48 \pm 0.10$ & 0.13 & 0.25 & 5.24 & 0.11 & 3.89 & $123 \pm 15$ \\
\hline
\end{tabular}


a)
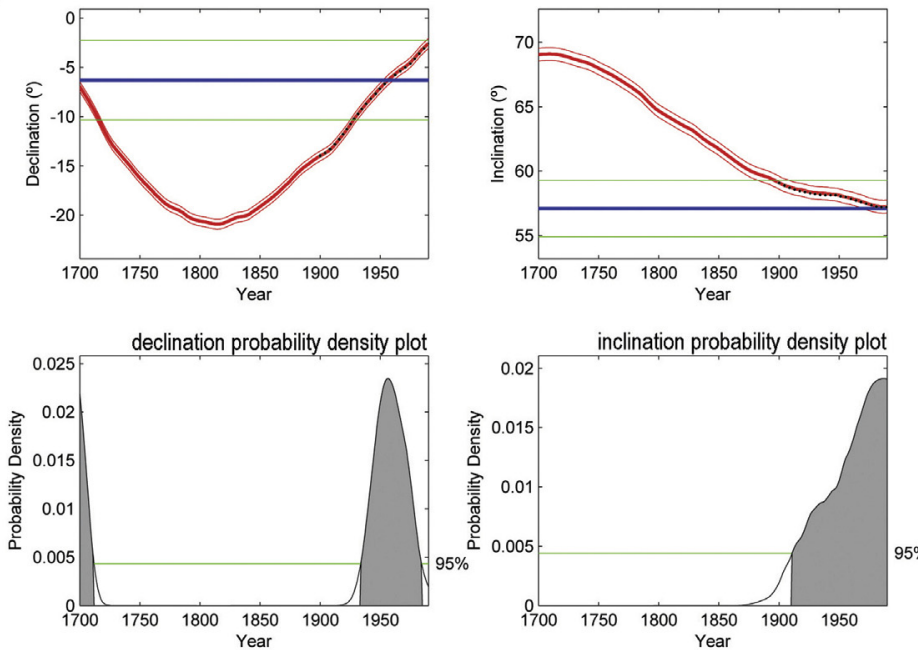

b)
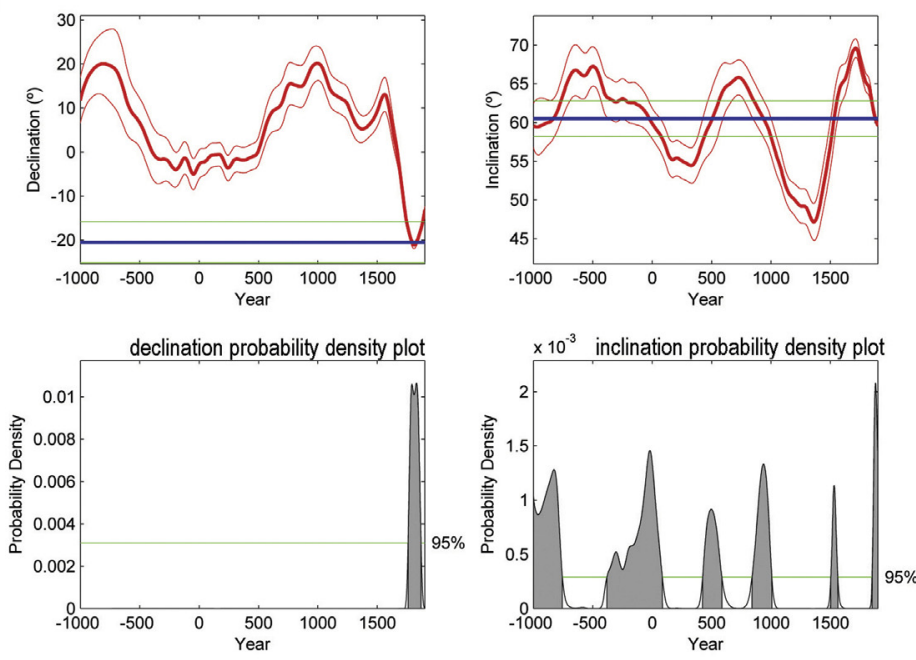

c)
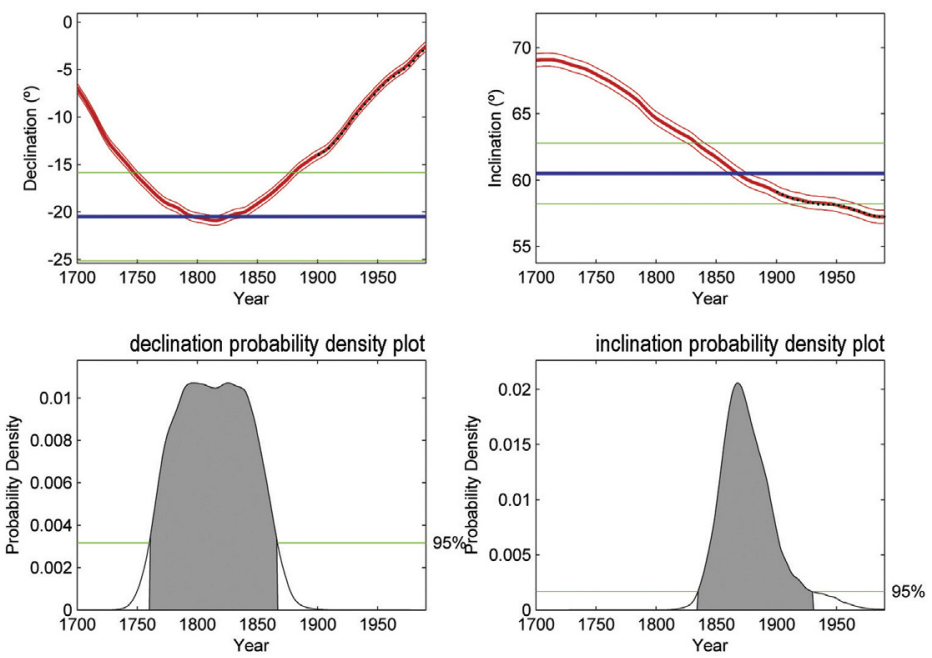

Lat: $41.78^{\circ} \mathrm{N}$

Long.: $1.94^{\circ} \mathrm{E}$

site: Forn de la Calç

structure: kiln C

D: $353.7^{\circ}$ I: $57.1^{\circ}$

model: Jackson et al., [6]

solution: 1938 to 1986

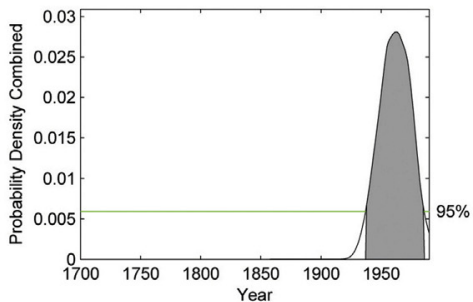

Lat:: $41.78^{\circ} \mathrm{N}$

Long.: $1.94^{\circ} \mathrm{E}$

site: Forn de la Calç

structure: kiln $\mathrm{T}$

D: $339.5^{\circ}$ I: $60.5^{\circ}$

model: SCHA.DIF.3K [7]

solution: 1844 to 1885

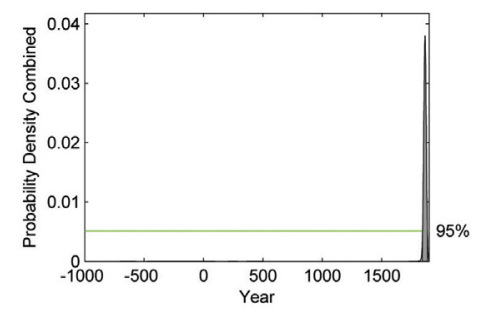

Lat:: $41.78^{\circ} \mathrm{N}$

Long.: $1.94^{\circ} \mathrm{E}$

site: Forn de la Calç

structure: kiln T

D: $339.5^{\circ}$ I: $60.5^{\circ}$

model: Jackson et al., [6]

solution: 1833 to 1879

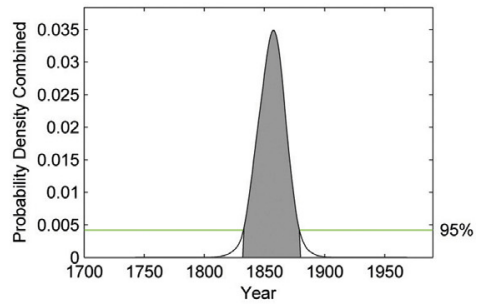

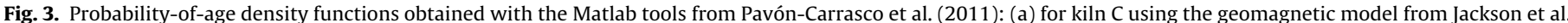

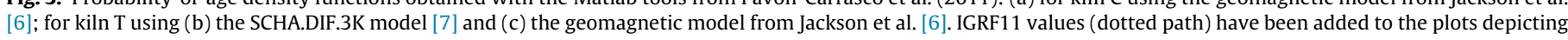

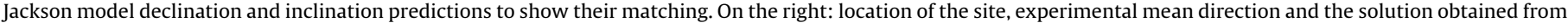
the combined (declination and inclination) probability function. 

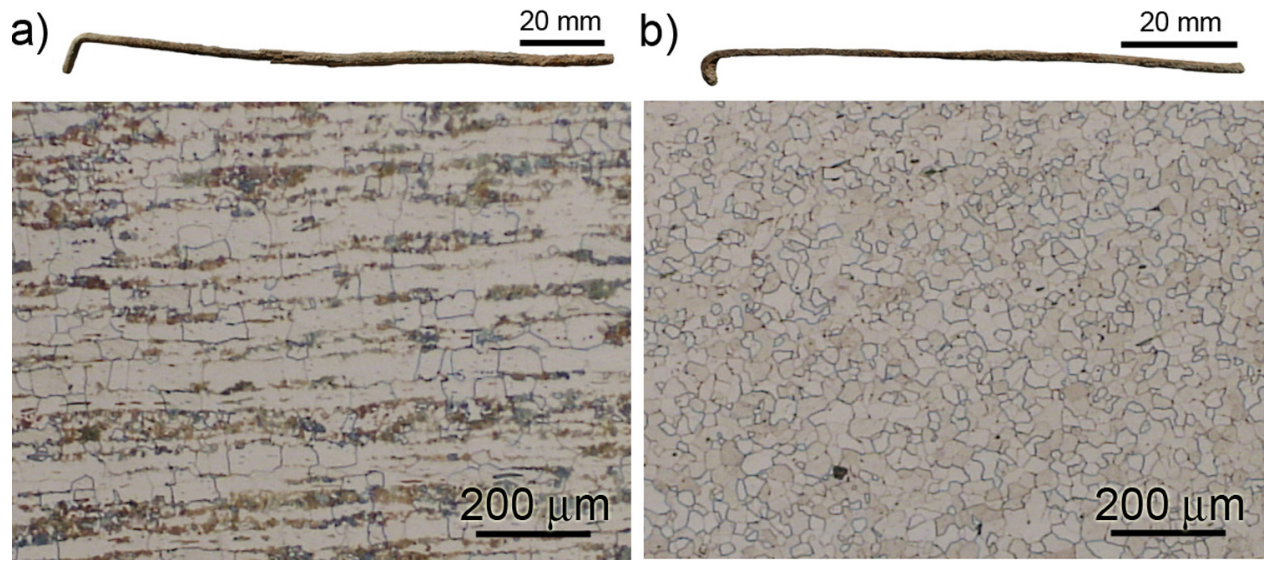

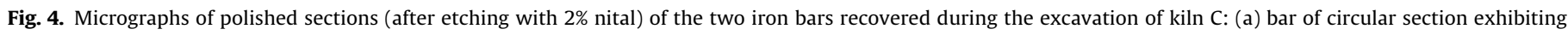
ferrite/pearlite banding; (b): bar of rectangular section made of pure ferrite. On the top: photographs of the bars.

\subsection{Thermoluminescence}

Through the plateau test, the range $220^{\circ} \mathrm{C}-260^{\circ} \mathrm{C}$ was identified for integration and comparison of TL signals between natural and irradiated samples. Supralinearity was found to be insignificant and no anomalous fading was detected. Table 2 summarizes the thermoluminescence dating results, on the basis of archaeological dose and annual dose the age of the last heating of the investigated brick was calculated indicating $1889 \pm 15$ AD.

\subsection{Metallographic microscope}

The two iron bars retrieved from the kiln interior show different typologies and compositions. A bar is $1.5 \mathrm{~m}$ long and has a circular section; its composition is a medium-carbon steel $(0.342 \%)$ exhibiting ferrite/pearlite banding (Fig. 4a) and a significant amount of impurities. The other bar is $1 \mathrm{~m}$ long and has a rectangular section; its composition is pure ferrite ( $\alpha$-Fe), (Fig. 4b).

From the metallographic data, two different metallurgic methods can be deduced. The ferrite/pearlite bar would have been produced from recycling scrap in a Martin-Siemens or an electric furnace. In contrast, the pure ferrite bar would have been produced by puddling in a forge.

\section{Dating discussion}

\subsection{Kiln $C$}

Despite the comparatively modern design of this kiln, there are not surviving witnesses of the kiln under operation. Former worker Mr. Mateu Comellas (personal communication) stated that during his youth, kiln $C$ was known but it was not under operation. Therefore the kiln was already abandoned during the forties of the 20th century. On the other hand, in a document dating from 1873, the site appears named as Forns del Raix. Forns is Catalan for kilns and Raix (presently spelled Raig) is Catalan for running, a term historically used to refer to a kiln that operates continuously. Therefore the name seems to imply that at that time, there were in the area more than one kiln with the peculiar typology of kiln C, we could assume that one of them was kiln $C$.

Archaeomagnetic dating of kiln $C$ suggests that the last firing of kiln C would be recent (Fig. 3a). In any case, this last use would have occurred later than 1938. However, thermoluminescence also dates last heating of the walls and produced an earlier date $(1889 \pm 15)$. We could presume that after being abandoned, the kiln was used to burn stubble or garbage resulting in surface remagnetization of the kiln walls, which did not affect the inner material used for thermoluminesce dating.

Finally, from the metallurgic methods, temporal information that contributes to the dating discussion can be inferred. The bars belonged to the baking rack system of the kiln, so these bars were used during the operation of the kiln and they are necessarily older than its last use. The pure ferrite bar was presumably produced in a traditional Catalan forge, a technology abandoned in the mid-19th century [13], with the very last reported production in 1878. Whereas the ferrite/pearlite bar was seemingly produced in a Martin-Siemens or an electric furnace, the first was introduced in Spain in 1899 [14] and the latter in 1906 [15]. Therefore, the kiln was operating at least later than 1899.

To sum up, and taking into account that the obtained dating values can bring more uncertainty than that mathematically estimated, the ensemble of results points to a last use for kiln $C$ in the early 20 th century.

\section{2. $\operatorname{Kiln} T$}

In spite of the lack of archaeological background, archaeomagnetic dating indicates clearly that the last use of kiln T was during the mid-19th century using both SCHA.DIF.3K and Jackson models. This age would indicate that lime works in the area bearing the three cylindrical holes excavated in the ground is almost continuous with the latter works in kiln $\mathrm{C}$ and the other kilns of CACiS.

\section{Conclusions}

The last use of kiln $\mathrm{T}$ has been constrained using archaeomagnetism. The dating tools indicate a quite recent time interval: $1844-1885$ or $1833-1879$ depending on the geomagnetic model used, both periods are mutually consistent.

The different dating approaches indicate that kiln $\mathrm{C}$ was under operation between 1873 and 1899 and, taking into account its early industrial typology, probably it was built some years before 1873 but possibly not before 1800 . The abandonment of the kiln would have occurred not later than 1904 (according to thermoluminescence dating), though archaeomagnetism points to a much more recent date for the abandonment, which in any case (according to oral sources) occurred not later than the forties of the 20th century.

\section{Acknowledgments}

We are grateful to Joan Vendrell and Roser Oduber from CACiS. Mateu Comellas is acknowledged for its explanations on the 
mid-20th century kilns of the site. We thank Sonia Moreno for its support during fieldwork. We also would like to acknowledge two anonymous reviewers for their helpful and insightful comments. This research was funded by the Spanish Ministerio de Ciencia y Innovación (project HAR2010-16953).

\section{References}

[1] J.B. Dumas, Traité de chimie appliquée aux arts, V.2, Béchet Jeune, Paris, 1830

[2] B. Fouzai, Ll. Casas, N.L. Ouazaa, A. Álvarez, Archaeomagnetic data from four Roman sites in Tunisia, J. Archaeol. Sci. 39 (2012) 1871-1882

[3] J.L. Kirschvink, The least-Squares line and plane and the analysis of paleomagnetic data, Geophys. J. R. Astronomical Soc. 62 (1980) 699-718.

[4] R. Fisher, Dispersion on a sphere, Proc. R. Soc. Lond. A Mat. Phys. Sci. 217 (1953) 295-305.

[5] F.J. Pavón-Carrasco, J. Rodríguez-González, M.L. Osete, M. Torta, A Matlab tool for archaeomagnetic dating, J. Archaeol. Sci. 38 (2011) 408-419.

[6] A. Jackson, A.R.T. Jonkers, M.R. Walker, Four centuries of geomagnetic secular variation from historical records, Philos. Trans. R. Soc. Lond. A Math. Phys. Eng. Sci. 358 (2000) 957-990.
[7] F.J. Pavón-Carrasco, M.L. Osete, M. Torta, L.R. Gaya-Piqué, A regional archeomagnetic model for Europe for the last 3000 years, SCHA.DIF.3K: applications to archeomagnetic dating, Geochem. Geophys. Geosyst. 10 (2009) Q03013.

[8] M.J. Aitken, Thermoluminescence Dating, Academic Press, New York, 1985.

[9] S.J. Fleming, Thermoluminescent dating: refinement of the quartz inclusion method, Archaeometry 12 (1970) 133-143.

[10] K.S.V. Nambi, M.J. Aitken, Annual dose conversion factors for TL and ESR dating, Archaeometry 28 (1986) 202-205.

[11] J.A. Dearing, R.J.L. Dann, K. Hay, J.A. Lees, P.J. Loveland, B.A. Maher, K. O’Grady, Frequency-dependent susceptibility measurements of environmental materials, Geophys. J. Int. 124 (1996) 228-240.

[12] Ll. Casas, P. Linford, J. Shaw, Archaeomagnetic dating of Dogmersfield Park brick kiln (Southern England), J. Archaeol. Sci. 34 (2007) 205-213.

[13] E. Tomàs, The Catalan process for the direct production of malleable iron and its spread to Europe and the Americas, Contrib. Sci. 1 (2) (1999) 225-232.

[14] Puig, R. Valls, Los ingenieros de montes en la exposición, La Vanguardia, Supplement (1889) 1-16.

[15] M.Á. Saez García, Una contribución a la historia de la siderurgia española: la fábrica de San Pedro de Araya (1848-1935) (PhD thesis), Euskal Herriko Unibertsitatea, 1998 . 